\title{
Immunolocalization of Proteoglycans in Meckel's Cartilage of the Rat
}

\author{
Khansa Taha Ababneh and Taiseer Hussain Al-Khateeb*
}

Faculty of Dentistry, Jordan University of Science and Technology, Irbid, Jordan

\begin{abstract}
The aim of this study was to investigate the presence and distribution of proteoglycans within Meckel's cartilage of rat embryos. A standard indirect immunoperoxidase technique was used on paraffin sections of rat heads. Sections were incubated with monoclonal antibodies recognising core protein epitopes in the proteoglycans versican and CD44. Polyclonal antibodies localized the proteoglycans decorin, biglycan and lumican. Versican was expressed by chondrocytes, but very weekly by the extracellular matrix. Decorin was strongly expressed by both of chondrocytes and the ECM. Both of biglycan and lumican were moderately expressed by chondrocytes, but weakly by the extracellular matrix. CD44 was weakly expressed by chondrocytes only, without staining of the ECM. It is concluded that Meckel's cartilage chondrocytes express the proteoglycans versican, decorin, biglycan, lumican and CD44 at variable levels during development in the rat. Such data are important for a greater understanding of the changes that take place during mandibular development. Further studies are needed to elucidate the exact role of proteoglycans during Meckel's cartilage and mandibular organogenesis.
\end{abstract}

Key Words: Immunohistochemistry, Meckel's cartilage, proteoglycans, rat.

\section{INTRODUCTION}

Proteoglycans (PG) are a group of macromolecules each composed of a core protein to which one or more highly anionic glycosaminoglycan (GAG) chains are attached through a specific sequence of trisaccharides: galactose-galactosexylose. Proteoglycans play essential roles in the development, maintenance of function and integrity of virtually all tissues [1]. They are pivotal in cell-cell, and cell-extracellular matrix (ECM) interactions, e.g. control of mineralization, control of collagen fibrillogenesis, in addition to acting as cell-surface receptors [2]. Furthermore, PG are believed to govern the process of cell movement in numerous physiological and pathological conditions [3].

During normal embryonic development in mammals, the mandible is formed from the mandibular process of the first branchial arch. The mesenchyme of the mandibular process is derived from cranial neural crest cells, and paraxial mesoderm [4]. While the mesoderm gives rise to muscular and vascular tissues, the neural crest cells give rise to the mandibular arch skeleton, including Meckel's cartilage [4]. The mandibular bone develops by intramembranous osteogenesis lateral to Meckel's cartilage. Meckel's cartilage is a pair of cylindrical rods of hyaline cartilage that give rise at their proximal ends to the malleus and incus of the middle ear [5]. The rostral (anterior to the mental foramen) and auricular (extending to the malleus) ends undergo endochondral type osteogenesis; the entire middle portion gets resorbed in the absence of any obvious formation of a calcified matrix and these cells undergo terminal cellular hypertrophy. However,

*Address correspondence to this author at the Faculty of Dentistry, Jordan University of Science \& Technology, Irbid, PO BOX 3030, Jordan; Tel: +962-2-7278662-274 (W), +962-2-7243111 (H); Fax: +962-2-7095123; E-mail: Khateeb@just.edu.jo the mid portion of the soft tissue of Meckel's cartilage, at the degenerating stage, gives rise to the sphenomandibular ligament [6]. It has been demonstrated that chondroitin sulphate proteoglycans (CSPG), namely the hyaluronan (HA)-binding PG aggrecan, are the main PG of hyaline cartilage [7]. Decorin, biglycan, fibromodulin and epiphycan have also been localised to hyaline cartilage [8]. These PG have been ascribed several important roles such as ECM assembly, control of mineralisation and acting as cell surface receptors. Temporo-spatial variation of PG expression and composition during embryogenesis regulate tissue formation and integrity. For example, quail embryonic aggrecan has been shown to curtail the ability of neural crest cells to migrate within tissues [9]. Similar roles may be played by Meckel's cartilage PG. It is still unclear how Meckel's cartilage influences the surrounding developing mandibular bone. However, PG in Meckel's cartilage appear to be essential in maintaining the cartilage in an un-mineralized state, for certain periods of time. PG may also be involved in communication with the surrounding mesenchymal tissues.

Epithelial-mesenchymal interactions play a pivotal role in histogenesis during mandibular development. Such interactions are mediated by the expression of various signalling molecules, such as PG and their components; the glycosaminoglycans (GAG) [10]. Animal studies, utilising 3-dimensional reconstruction, indicate that the mandible mainly grows at its periphery, and that this growth is regulated by paracrine signalling from Meckel's cartilage and the developing tooth buds [11]. This signalling is probably mediated by a variety of macromolecules such as transforming growth factors-beta (TGF- $\beta$ ), bone morphogenetic proteins (BMP) and PG [11]. In an attempt to understand the role of PG in the development of the growing mandible, this study was conducted to investigate the expression and distribution of a 
number of PG species at Meckel's cartilage during in utero development in a mouse model utilising immunohistochemistry.

\section{MATERIALS AND METHODS}

\section{Antibodies}

Paraformaldehyde and sodium cacodylate (BDH Chemical Ltd Poole, England) were used for tissue fixation. A sledge base microtome (Leitz) was used to cut sections. For immunolocalization, a kit utilising a standard indirect immunoperoxidase method was used (Vectastain Quick kit, Vector Lab., California). The enzyme chondroitinase ABC (Sigma Chemical CO) was used to increase accessibility of the antibodies to their epitopes. Well-characterised antibodies were used and are listed in Table 1. These include the monoclonal (MAb) antibody 12C5 against versican, the polyclonal antibody (PAb) LF-113 against murine decorin, the (PAb) LF-106 against murine biglycan, a PAb recognising the core protein of lumican, and the MAb Hermes I against CD44.

\section{METHODS}

\section{Tissue Preparation}

This animal study was reviewed and approved by the institutional ethics committee. The specimens examined included rat heads of embryonic stages E18, E19 and E20, corresponding to post conception days 18, 19 and 20. These were fixed in $4 \%$ paraformaldehyde and $0.1 \mathrm{M} \mathrm{Na}$ cacodylate buffer for up to $48 \mathrm{~h}$ at $4^{\circ} \mathrm{C}$. The specimens were dehydrated in $90 \%$ ethanol, embedded in paraffin wax, and 5-10 $\mu \mathrm{m}$ sections were cut. To observe normal histology, haematoxylin and eosin sections were prepared for light microscopic examination.

\section{Immunohistochemical Staining}

Prior to staining, the sections were de-paraffinized in xylene and rehydrated for $5 \mathrm{~min}$ in descending concentrations of alcohol (100\% twice, $95 \%$ and $70 \%$ ethanol), water and PBS. To increase antibody access to epitopes, sections were pre-treated with chondroitinase ABC $0.1 \mathrm{IU} / \mathrm{mL}$ (Sigma) in $0.1 \mathrm{M}$ Tris buffer containing $0.1 \% \mathrm{BSA}, \mathrm{pH} 7.2$ at $37^{\circ} \mathrm{C}$ for $1 \mathrm{~h}$. After enzymatic pre-treatment the sections were rinsed thoroughly in PBS and Tween (Polyoxyethylene 20 sorbitan monolaurate, Fisher Scientific Ltd., Loughborough, UK) for $15 \mathrm{~min}$, and incubated for $5 \mathrm{~min}$ with $3 \%$ $\mathrm{H}_{2} \mathrm{O}_{2}$ in water to eliminate endogenous peroxidase activity. The sections were incubated for $10 \mathrm{~min}$ in working solution of normal horse serum, (Vectastain Quick kit, Vector lab., California) in order to block background staining. Primary antibodies were added at working concentrations, which are presented in Table 1. These antibodies were all diluted in PBS buffer containing 1.5\% horse serum (Vectastain Quick kit, Vector lab., California), and left on the sections for 60 min at room temperature. The slides were rinsed twice in PBS and Tween for $5 \mathrm{~min}$ and incubated with the biotinylated secondary antibody (raised in horse and recognises rabbit, mouse, goat, bovine and sheep $\mathrm{IgG}$, Vectastain Quick kit, Vector Lab., California) for $10 \mathrm{~min}$ at room temperature. After two 5-min rinses in PBS and Tween, the sections were incubated in streptavidin/peroxidase complex solution for 5 min (Vectastain Quick kit, Vector lab., California) and rinsed as above. The sections were then incubated with the peroxidase substrate solution, containing diaminobenzidine (DAB) until the brown stain developed intensely. The sections were thoroughly rinsed with double distilled water, counterstained with haematoxylin and rinsed in water, PBS and water again. They were dehydrated in ethanol, cleared in xylene and mounted for LM examination. Photomicrographs were taken with Leica microscope, using Kodak Ektachrome films.

\section{Controls}

Positive and negative control sections were used. With polyclonal (rabbit) antibodies against decorin, biglycan and lumican, some negative control sections were incubated with normal rabbit serum (concentration 1:1000, Sigma), which does not interact with the tissues studied. With monoclonal antibodies, serum or mouse immunoglobulin (MIG, Sigma, concentration 1:500) were used instead of the primary antibodies. Other sections were incubated with PBS in place of the primary antibody. The developing tooth buds in each section were used as positive/negative control tissues, based on findings of previous studies $[16,17]$.

Table 1. Details of the Antibodies Used in this Investigation

\begin{tabular}{|c|c|c|c|c|c|}
\hline Antibody & Epitope & Type & Dilution & Source & Reference \\
\hline $12 \mathrm{C} 5$ & $\begin{array}{l}\text { Hyaluronate binding } \\
\text { region of versican }\end{array}$ & Monoclonal mouse IgG1 & $1: 200$ & $\begin{array}{c}\text { Purchased from Dr. R.A. Asher, Developmental } \\
\text { Studies Hybridoma Bank, Iowa, USA }\end{array}$ & Asher et al. [12] \\
\hline LF-113 & $\begin{array}{l}\text { Core protein epitopes of } \\
\text { murine decorin }\end{array}$ & Polyclonal rabbit IgG & $1: 100$ & $\begin{array}{l}\text { A generous gift from Professor L. Fisher, } \\
\text { National Institute of Health, USA }\end{array}$ & Fisher et al. [13] \\
\hline LF-106 & $\begin{array}{l}\text { Core protein epitopes of } \\
\text { murine biglycan }\end{array}$ & Polyclonal rabbit IgG & $1: 100$ & $\begin{array}{l}\text { A generous gift from Professor L. Fisher, } \\
\text { National Institute of Health, USA }\end{array}$ & Fisher et al. [13] \\
\hline Anti-lumican & Core protein epitopes & Polyclonal, rabbit IgG & $1: 200$ & $\begin{array}{l}\text { A generous gift from Professor J R Hassel, } \\
\text { University of Pittsburgh, Pennsylvania, USA }\end{array}$ & Chakravarti et al. [14] \\
\hline Hermes 1 & $\begin{array}{c}\text { The N-terminal Hyaluronate } \\
\text { binding domain of CD44 }\end{array}$ & Monoclonal rat IgG2 & $1: 10$ & $\begin{array}{c}\text { Developmental Studies Hybridoma Bank, } \\
\text { Iowa, USA }\end{array}$ & Picker et al. [15] \\
\hline
\end{tabular}




\section{RESULTS}

\section{Immunolocalization of Versican}

After incubation with MAb 12C5 and chondroitinase $\mathrm{ABC}$ pre-treatment, the following results were obtained (Fig. $\mathbf{1 A}, \mathbf{B}, \mathbf{C})$. At E18 there was a positive staining of chondrocytes of Meckel's cartilage. Similar distribution and intensity of staining were observed in the E19 and E20 rat embryos. In all embryonic stages, there was only very weak staining of the ECM.

\section{Immunolocalization of Decorin}

Following incubation with LF-113 (a PAb which specifically recognises murine decorin), and chondroitinase $\mathrm{ABC}$ pre-digestion, an intense positive staining of chondrocytes and ECM of Meckel's cartilage was observed at the embryonic stages E18, E19 and E20 (Fig. 1D, E, F).

\section{Immunolocalization of Biglycan}

Following incubation with LF-106 (a PAb which specifically recognises murine biglycan), with chondroitinase $\mathrm{ABC}$ pre-digestion, positive staining of chondrocytes was observed at E18. More intense staining was evident at E19 and E20. The ECM was mildly stained at the three stages (E18 to 20) (Fig. 1G, H, I).

\section{Immunolocalization of Lumican}

Following incubation of sections with the PAb recognising core protein epitopes in lumican, at the E18 stage, weak immunoreactivity was observed in the chondrocytes and ECM of Meckel's cartilage. E19 cartilage showed moderate immunoreactivity, and at E20 Meckel's cartilage showed strong immunoreactivity. The ECM was mildly stained at the three stages (E18 to 20) (Fig. 1J, K, L).

\section{Immunolocalization of CD44}

After incubation of sections with MAb Hermes 1, which recognises CD44, very weak immunoreactivity was observed on chondrocytes at the periphery of Meckel's cartilage at the three stages examined (E18-E20). No evidence of staining could be seen in the ECM (Fig. 1M, N, O).

\section{Controls}

Control sections where the primary antibody was substituted with PBS, mouse immunoglobulin or rabbit serum, were all negative (Fig. 1P). The developing tooth buds and dental tissues, such as the pulp and dentine in each section, which were used as positive/negative control sections (Fig. 1Q, R), exhibited findings consistent with previous studies $[16,17]$.

\section{DISCUSSION}

During intra uterine life, the ECM of Meckel's cartilage remodels by the action of proteolytic enzymes secreted by its own chondrocytes, and most of the cartilage disintegrates soon after the onset of mandibular bone formation. Although it is generally accepted that Meckel's cartilage is essential for mandibular growth and development, the exact role of this cartilage, and thus, the roles of the tissue factors expressed within it, are still unclear.
The midportion of Meckel's cartilage in rats and mice disappears soon after birth, probably by cellular resorption of the chondrocytes in the anterior part of the midportion, and by differentiating into fibroblastic cells in the posterior part of the midportion [18]. In the present study, we have selected rat embryonic stages E18-E20 (usually, the last gestational day) before any disintegration of the cartilage rods, or transformation of the chondrocytes into fibroblasts within the midportion of Meckel's cartilage has taken place. It is expected that in newborn rats the anterior part of the midportion of Meckel's cartilage may be completely missing, and changes in the posterior part of the midportion may have started [18]. Therefore, in the present work only embryonic Meckel's cartilage was studied. Most previous studies have investigated earlier stages Meckel's cartilage; for example, Lee et al. [19] investigated Meckel's cartilage at embryonic days 15-18. Moreover, some PG like versican could not be detected at earlier embryonic stages such as E15 [19]. Our aim was to investigate PG in Meckel's cartilage at later embryonic stages just before chondrocyte transformation, or disappearance, have occurred.

Meckel's cartilage chondrocytes share many phenotypic characteristics with other cartilaginous cells. However, they show some differences from trunk cartilage chondrocytes. For example, Meckel's cartilage chondrocytes are the only cartilage cells that are capable of producing type I collagen in tissue cultures [6]. This probably reflects the different origins of this cartilage as, unlike other cartilage, which is derived from mesoderm, Meckel's cartilage originates from neural crest ectomesenchyme [6]. We have shown that the PG species versican, the small leucine-rich proteoglycans (SLRPs) decorin, biglycan and lumican, and the cell surface HA-binding PG CD44 are present in Meckel's cartilage of the rat during in utero mandibular development with variable degrees. Although CSPG have previously been shown to be present in Meckel's cartilage [2], to date, this is first study to describe the expression of a wide range of PG in Meckel's cartilage.

Versican (also known as PG-M) is a large CSPG of the ECM. In various developing embryonic tissues, versican is transiently expressed and plays important roles in cell adhesion [20], migration [21], proliferation, and differentiation [22]. It localizes in various tissues both in fetal and adult animals [21, 23-25]. In particular, it is expressed in prechondrogenic mesenchyme, and during the transition to cartilage its expression becomes restricted to the periphery of the newly formed cartilage [21]. In addition, versican has been isolated from rat dental pulp [26], periodontium [27], and developing mandibular condylar cartilage [28]. It has been suggested that versican is involved in positively regulating the formation of the mesenchymal matrix and the onset of chondrocyte differentiation through the attached chondroitin sulfate chains [29]. Another study [30] strongly suggests that mature versican is essential for precartilage aggregation and subsequent cartilage differentiation.

In developing cartilage, versican is transiently expressed at a high level in the mesenchymal condensation area and rapidly disappears during cartilage development [31]. Immunohistochemical studies on developing limb bud cartilage revealed that an area positive for versican gradually shifts out of the diaphysis and is replaced by an area positive for 
Proteoglycans

Versican $(x 100)$

Decorin (x100)

Biglycan (x200)

Lumican (x200)

CD44 (x200)

Controls (Px200; Q,Rx100)
E18
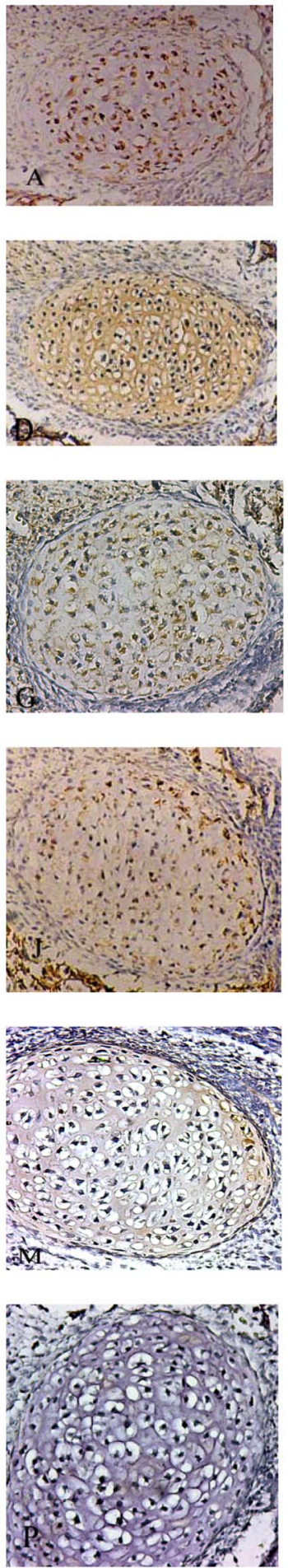

E19
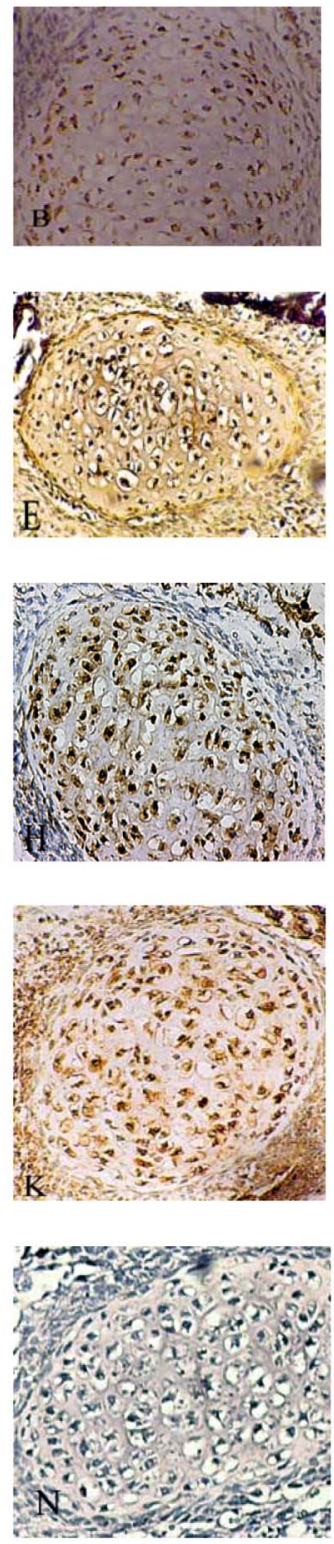

E20
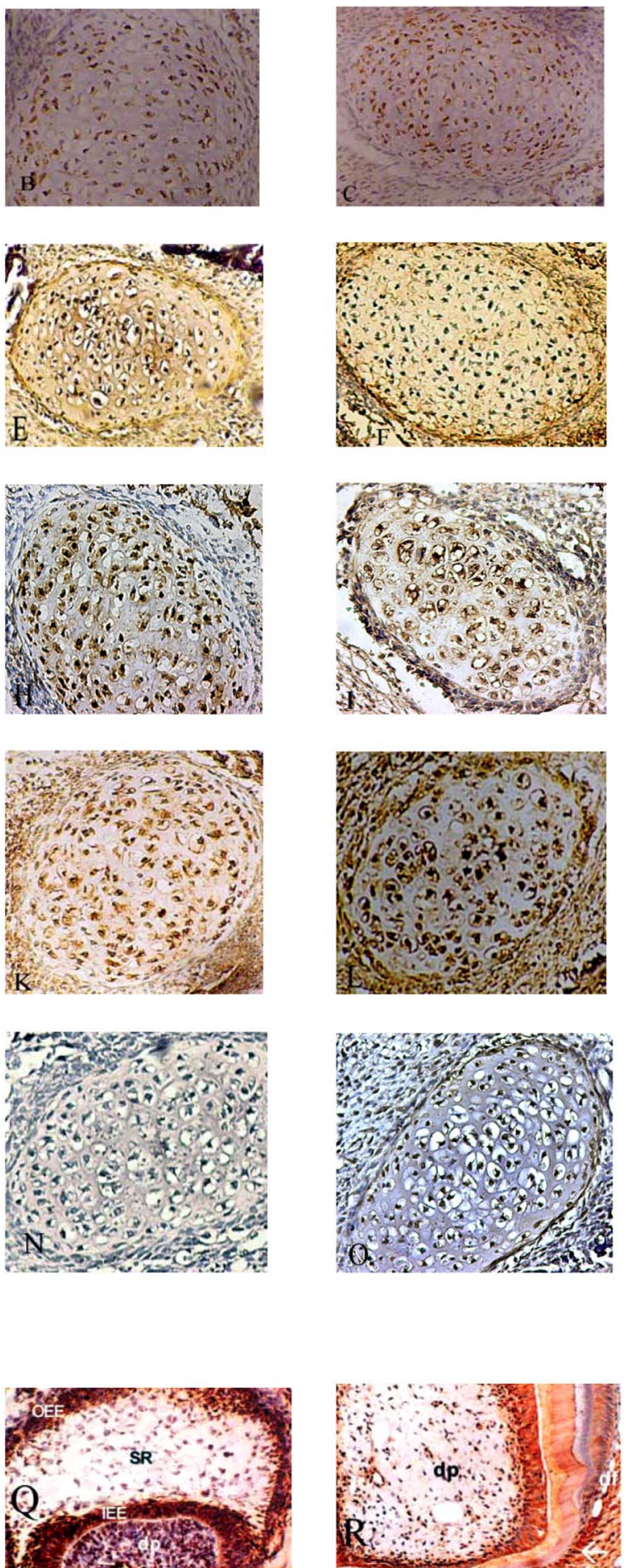

Fig. (1). Immunoperoxidase staining for Versican showing positive staining of moderate intensity on Meckel's cartilage chondrocytes and weak staining within the ECM at all embryonic stages $(\mathbf{A}, \mathbf{B}, \mathbf{C})$. Decorin showed an intense positive staining on chondrocytes and within the ECM at all embryonic stages $(\mathbf{D}, \mathbf{E}, \mathbf{F})$. Biglycan was moderately expressed at E18 (G), and more intense staining at later stages $(\mathbf{H}, \mathbf{I})$. Staining for Lumican on the chondrocytes and ECM was weak at E18 (J), moderate at E19 (K), and intense at E20 (L). Immunoperoxidase staining for CD44 showed very weak staining on chondrocytes at all stages, without any staining within the ECM (M, N, O). P, Q and R represent the control sections.

P: negative control section; Q: positive staining for biglycan in the enamel organ and dental papilla of a developing molar tooth bud at the E19 stage; R: positive staining for decorin in the dental papilla, odontoblasts and dentin in a developing tooth bud. OOE: outer enamel epithelium; SR: stellate reticulum; IEE: inner enamel epithelium; dp: dental pulp, df: dental follicle. 
aggrecan [24]. Differentiating chondrocytic cells showed similar expression patterns of these molecules [29]. Therefore, it was generally accepted that mature chondrocytes do not express versican (but express aggrecan). However, although versican has not been detected by immunohistochemical studies, constitutive low level transcription of the versican gene has been observed in cartilage and chondrocytes [31, 32]. Furthermore, biochemical studies demonstrated the presence of versican in human articular cartilage from the fetal stage to mature adult [33]. Unlike previous immunohistochemical studies, we have demonstrated positive immunostaining of versican within chondrocytes of Meckel's cartilage. It is possible that the expression of versican is a unique feature of Meckel's cartilage at later embryonic stages.

In the present study, versican was expressed by Meckel's cartilage chondrocytes in all embryonic stages, with no changes detected in the intensity of staining as the embryos matured. Our findings are in general agreement with those of Ishizeki and Nawa [34], who demonstrated the expression of CSPG, using immunohistochemical methods, in addition to toluidine and Alcian blue staining. However, our findings contrast with those of Lee et al. [19], who were not able to demonstrate immunoreactivity to versican in Meckel's cartilage. The reason for this disagreement may be that, in their study, Lee et al. [19] have included earlier stage Meckel's cartilage (embryonic days 15 to 18 ), whereas in our study, later stages (E18 to E 20) were investigated. Another reason may be that Lee et al. [19] have used a different antibody. They have used the MAb (5D5) which recognises the core proteins of large PG, such as versican, neurocan and brevican. The antibody used in our study (12C5) is a more specific antibody, which specifically recognises the HA-binding region of versican core protein.

The SLRPs belong to the large family of leucine-rich repeat proteins, which are characterized by multiple adjacent domains bearing a common leucine-rich motif. They can be divided into several sub-families based on their gene organization, the number of leucine-rich repeats and the type of GAG chain substituent. Decorin and biglycan are part of one subfamily, whereas fibromodulin and lumican are part of a second subfamily. The GAG chains have been associated with the interaction with several growth factors, and enable the SLRPs to provide a sink for growth factor accumulation within the extracellular matrix. The SLRPs can therefore, help modulate chondrocyte metabolism by regulating growth factor access to the cells [35].

Decorin and biglycan can be detected in fetal cartilage and bone [36]. Although decorin is involved in the organization of collagen fibrils, in the modulation of collagen metabolism and in interactions with various glycoproteins, retinoic acid and growth factors, e.g. TGF- $\beta$ [37], the functions of biglycan are not well understood. It may participate in the control of chondrocyte proliferation [31]. In vitro studies of human articular cartilage have shown that the expression level of decorin increases and that of biglycan decreases with age [38]. Within developing bone, biglycan is localized to the walls of the osteocyte lacunae and bone cell surface, whilst decorin is present throughout the osteoid matrix and associated with bone cells associated with osteogenic and non-osteogenic layers of the periosteum [36]. We have found that decorin is expressed by chondrocytes and surrounding ECM without any change in intensity of staining in the three embryonic stages examined. As for biglycan, staining was less intense than decorin, but gradually increased throughout development. Similarly, Kavanagh and Ashhurst [39], investigating the immunolocalization of biglycan during development and aging of articular cartilage in the rabbit knee joint, found that biglycan is present in the deeper regions of the epiphyseal cartilage, which eventually ossifies, but could not be detected in the interzone, the region from which the articular cartilage develops and maintains its cartilaginous nature after birth. Decorin and biglycan have been isolated from predentine, predentine-dentine interface and the mineralised dentine ECM [40]. Milan et al. [41] have demonstrated that the composition and functions of decorin and biglycan differ with transition from the non-mineralised predentine towards the mineralised dentine matrix. Furthermore, it was found that with this transition from the nonmineralised to mineralised dentine, there was an increasing affinity to hydroxyapatite, which was predominantly facilitated through GAG chains [42]. Based on the above findings, our results of a sustained expression of decorin and biglycan in Meckel's cartilage might suggest a role of these SLRPs in inhibiting mineralisation of this cartilage.

In the present study, lumican was gradually upregulated throughout embryonic stages E18 to E20. In accordance with our results, Ying et al. [43] have demonstrated, using northern plot and in situ hybridisation, that in earlier stages mouse embryos, there is almost no lumican expression, but that the expression of this PG increases with organ development and function.

CD44 is an adhesion molecule distinct from cadherin and integrins. This protein functions as a HA receptor and is involved in cell migration [44]. In vitro studies suggest that CD44 is expressed in chondrocytes [45]. In the present study, CD44 was weakly expressed by Meckel's cartilage chondrocytes. This pattern of CD44 expression in rat Meckel's cartilage is different from that previously reported in rat tibial cartilage [46]. However, it is consistent with its distribution in the rat mandibular condylar cartilage [47]. Cranial bone and cartilage, including Meckel's cartilage and mandibular condylar cartilage, originate in neural crestderived mesenchyme [48]. In contrast, bones and cartilage in limbs are derived from lateral plate mesoderm. Thus, Meckel's cartilage has a different developmental origin from tibial cartilage. Therefore, the different pattern of CD44 expression observed in these two types of cartilage may be due to their different origins. In fact, CD44 is used as a marker of neural-crest-derived cells and embryonic stem cells [49].

The temporal expression of PG during various stages of development found herein, suggests that the expression of PG may be up- or down-regulated by chondrocytes as necessary for cell-cell or cell-ECM signalling within Meckel's cartilage, or between chondrocytes of Meckel's cartilage and the surrounding mesenchymal tissues and developing alveolar bone. Changes in the expression and chemical composition of various macromolecules, including PG and growth factors, are well-known events during histogenesis and morphogenesis of various tissues during orofacial development, including mineralised tissues such as tooth dentine [40-42]. The very exact role of PG in Meckel's cartilage 
cannot be readily revealed from the present work, however, we postulated, based on the functions of PG reported by other studies [50] that Meckel's cartilage PG may inhibit mineralization of the cartilage during mandibular development, where signalling from Meckel's cartilage chondrocytes and/or ECM is believed to be necessary for mandibular development, which may be mediated by PG. It is known that the functions of PG including SLRPs depend upon their core protein and GAG chains. SLRPs interact, via their core protein, with fibrillar collagen, thus regulating fibril diameter and fibril-fibril interactions. Attachment of core proteins to collagen also limits access of collagenase to its substrate, thereby protecting collagen from proteolytic action [50]. The function of SLRPs, such as decorin, biglycan and lumican is best illustrated by the abnormal phenotypes in knock-out mice. Inhibition of decorin expression was associated with thinning of the skin, accumulation of loose connective tissue in the subdermal layer, abrupt fracture and dissection of the skin between the deeper dermis and the fascia [51]. Biglycan knockout mice demonstrated reduced growth rate, decreased bone mass and differences in bone shape, when compared to normal mice [52]. Absence of lumican produces skin laxity and corneal opacity, with an increased proportion of abnormally thick collagen fibrils and delayed corneal epithelial wound healing [53] Therefore, the PG of Meckel's cartilage are probably involved in similar functions, including regulation of collagen fibrillogenesis, preservation of Meckel's cartilage integrity, inhibition of cell proliferation, inhibition of Meckel's cartilage mineralization and possibly influencing the developing mandibular bone surrounding Meckel's cartilage.

The results presented here show how the distributions of the PG versican, decorin, biglycan, lumican and CD44 vary during development in rat Meckel's cartilage. In addition, they suggest that the Meckel's cartilage chondrocytes are a distinct population of cells. Such data are important for a greater understanding of the changes that take place during mandibular development. Further studies are needed to elucidate the exact role of PG during Meckel's cartilage and mandibular organogenesis.

\section{REFERENCES}

[1] Iozzo RV. Basement membrane proteoglycans: from cellar to ceiling. Nat Rev Mol Cell Biol 2005; 6: 646-56.

[2] Ishizeki K, Hiraki Y, Kubo M, Nawa T. Sequential synthesis of cartilage and bone marker proteins during transdifferentiation of mouse Meckel's cartilage chondrocytes in vitro. Int J Dev Biol 1997; 41: 83-9.

[3] Cattaruzza S, Perris R. Proteoglycan control of cell movement during wound healing and cancer spreading. Matrix Biol 2005; 24: 400-17.

[4] Osumi-Yamashita N, Ninomiya Y, Eto K. Mammalian craniofacial embryology in vitro. Int J Dev Biol 1997; 41: 187-94.

[5] Ito Y, Bringas P Jr, Mogharei A, Zhao J, Deng C, Chai Y. Receptor-regulated and inhibitory Smads are critical in regulating transforming growth factor beta-mediated Meckel's cartilage development. Dev Dyn 2002; 224: 69-78.

[6] Ishizeki K, Shinagawa T, Nawa T. Origin-associated features of chondrocytes in mouse Meckel's cartilage and costal cartilage: an in vitro study. Ann Anat 2003; 185: 403-10.

[7] Pinheiro MC, Joazeiro PP, Mora OA, Toledo OM. Ultrastructural and immunohistochemical analysis of proteoglycans in mouse pubic symphysis. Cell Biol Int 2003; 27: 647-55.

[8] Iozzo RV. The family of the small leucine-rich proteoglycans: key regulators of matrix assembly and cellular growth. Crit Rev Biochem Mol Biol 1997; 32: 141-74.
[9] Kerr RS, Newgreen DF. Isolation and characterization of CSPGfrom embryonic quail that influence neural crest cell behaviour. Dev Biol 1997; 192: 108-24.

[10] Thesleff I, Vaahtokari A, Kettunen P, Aberg T. Epithelialmesenchymal signalling during tooth development. Connect Tissue Res 1995; 32: 9-15.

[11] Ramaesh T, Bard JB. The growth and morphogenesis of the early mouse mandible: a quantitative analysis. J Anat 2003; 203: 213-22.

[12] Asher RA, Scheibe RJ, Keiser HD, Bignami A. On the existence of a cartilage-like proteoglycan and link proteins in the central nervous system. Glia 1995; 13: 294-308.

[13] Fisher LW, Stubbs JT 3rd, Young MF. Antisera and cDNA probes to human and certain animal model bone matrix noncollagenous proteins. Acta Orthop Scand Suppl 1995; 266: 61-5.

[14] Chakravarti S, Stallings RL, SundarRaj N, Cornuet PK, Hassell JR. Primary structure of human lumican (keratan sulfate proteoglycan) and localization of the gene (LUM) to chromosome 12q21.3-q22. Genomics 1995; 27: 481-8.

[15] Picker LJ, De los Toyos J, Telen MJ, Haynes BF, Butcher EC. Monoclonal antibodies against the CD44 [In(Lu)-related p80], and Pgp-1 antigens in man recognize the Hermes class of lymphocyte homing receptors. J Immunol 1989; 142: 2046-51.

[16] Matsuura T, Duarte WR, Cheng H, Uzawa K, Yamauchi M. Differential expression of decorin and biglycan genes during mouse tooth development. Matrix Biol 2001; 20: 367-73.

[17] Sone S, Nakamura M, Maruya Y, et al. Expression of versican and ADAMTS during rat tooth eruption. J Mol Histol 2005; 36: 281-8.

[18] Harada Y, Ishizeki K. Evidence for transformation of chondrocytes and site-specific resorption during the degradation of Meckel's cartilage. Anat Embryol (Berl) 1998; 197: 439-50.

[19] Lee I, Ono Y, Lee A, Omiya K, Moriya Y, Takagi M. Immunocytochemical localization and biochemical characterization of large proteoglycans in developing rat bone. J Oral Sci 1998; 40: 77-87.

[20] Yamagata M, Shinomura T, Kimata K. Tissue variation of two large chondroitin sulfate proteoglycans (PG-M/versican and PGH/aggrecan) in chick embryos. Anat Embryol 1993; 187: 433-44.

[21] Landolt RM, Vaughan L, Winterhalter KH, Zimmermann DR. Versican is selectively expressed in embryonic tissues that act as barriers to neural crest cell migration and axon outgrowth. Development 1995; 121: 2303-12.

[22] Kishimoto J, Ehama R, Wu L, Jiang S, Jiang N, Burgeson R E. Selective activation of the versican promoter by epithelial- mesenchymal interactions during hair follicle development .Proc Natl Acad Sci USA 1999; 96: 7336-41.

[23] Zimmermann DR, Dours-Zimmermann MT, Schubert M, Bruckner-Tuderman L. Versican is expressed in the proliferating zone in the epidermis and in association with the elastic network of the dermis. J Cell Biol 1994; 124: 817-25.

[24] Bode-Lesniewska B, Dours-Zimmermann MT, Odermatt BF, Briner J, Heintz PU, Zimmermann DR. Distribution of the large aggregating proteoglycan versican in adult human tissues. J Histochem Cytochem 1996; 44: 303-12.

[25] Shibata S, Kaneko S, Yanagishita M, Yamashita Y. Histochemical localization of hyaluronan and versican in the rat molar dental pulp. Arch Oral Biol 1999; 44: 373-6.

[26] Shibata S, Yoneda S, Yanagishita M, Yamashita Y. Isolation of proteoglycan (versican) aggregate from rat dental pulp. Arch Oral Biol 2000; 45: 563-8.

[27] Sato R, Yamamoto H, Kasai K, Yamauchi M. Distribution pattern of versican, link protein and hyaluronic acid in the rat periodontal ligament during experimental tooth movement. J Periodont Res 2002; 37: 15-22.

[28] Shibata S, Fukada K, Suzuki S, Ogawa T, Yamashita Y. Histochemical localization of versican, aggrecan and hyaluronan in the developing condylar cartilage of the fetal rat mandible. J Anat 2001; 198: 129-35.

[29] Kamiya N, Watanabe H, Habuchi H, et al. Versican/PG-M regulates chondrogenesis as an extracellular matrix molecule crucial for mesenchymal condensation. J Biol Chem 2006; 281: 2390-400.

[30] Williams DR Jr, Presar AR, Richmond AT, Mjaatvedt CH, Hoffman S, Capehart AA. Limb chondrogenesis is compromised in the versican deficient hdf mouse. Biochem Biophys Res Comm 2005; 334: 960-6.

[31] Shibata S, Fukada K, Imai H, Abe T, Yamashita Y. In situ hybridization and immunohistochemistry of versican, aggrecan and link 
protein, and histochemistry of hyaluronan in the developing mouse limb bud cartilage. J Anat 2003; 203: 425-32.

[32] Kolettas E, Buluwela L, Bayliss MT, Muir HI. Expression of cartilage-specific molecules is retained on long-term culture of human articular chondrocytes. J Cell Sci 1995; 108: 1991-9.

[33] Sztrolovics R, Grover J, Cs-Szabo G, et al. The characterization of versican and its message in human articular cartilage and intervertebral disc. J Orthop Res 2002; 20: 257-66.

[34] Ishizeki K, Nawa T. Further evidence for secretion of matrix metalloproteinase-1 by Meckel's chondrocytes during degradation of the extracellular matrix. Tissue Cell 2000; 32: 207-15.

[35] Roughley PJ. The structure and function of cartilage proteoglycans. Eur Cell Mat 2006; 12: 92-101.

[36] Bianco P, Fisher LW, Young MF, Termine JD, Robey GP. Expression and localization of the two small proteoglycans biglycan and decorin in developing human skeletal and non-skeletal tissues. J Histochem Cytochem 1990; 38: 1549-63.

[37] Kresse H, Hausser H, Schönherr E. Small proteoglycans. Experientia 1993; 49: 403-15.

[38] Roughley PJ, Lee ER. Cartilage proteoglycans: structure and potential functions. Microsc Res Tech 1994; 28: 385-97.

[39] Kavanagh E, Ashhurst DE. Development and aging of the articular cartilage of the rabbit knee joint: distribution of biglycan, decorin, and matrilin-1. J Histochem Cytochem 1999; 47: 1603-15.

[40] Moseley R, Waddington RJ, Sloan AJ, Smith AJ, Hall RC, Embery $\mathrm{G}$. The influence of fluoride exposure on dentin mineralization using an in vitro organ culture model. Calcif Tissue Int 2003; 73: 470-5.

[41] Milan AM, Sugars RV, Embery G, Waddington RJ. Dentinal proteoglycans demonstrate an increasing order of affinity for hydroxyapatite crystals during the transition of predentine to dentine. Calcif Tissue Int 2004; 75: 197-204.

[42] Sugars RV, Milan AM, Brown JO, Waddington RJ, Hall RC, Embery $\mathrm{G}$. Molecular interaction of recombinant decorin and biglycan with type I collagen influences crystal growth. Connect Tissue Res 2003; 44(Suppl 1): 189-95.

[43] Ying S, Shiraishi A, Kao CW, et al. Characterization and expression of the mouse lumican gene. J Biol Chem 1997; 272: 30306-13.

[44] Spessotto P, Rossi FM, Degan M, et al. Hyaluronan-CD44 interaction hampers migration of osteoclast-like cells by down-regulating MMP-9. J Cell Biol 2002; 158: 1133-44.

[45] Knudson CB. Hyaluronan and CD44: strategic players for cellmatrix interactions during chondrogenesis and matrix assembly. Birth Defects Res C Embryo Today 2003; 69: 174-96.

[46] Nakamura H, Ozawa H. Immunolocalization of CD44 and the ERM family in bone cells of mouse tibiae. J Bone Miner Res 1996; 11: $1715-22$.

[47] Nakamura H, Kato R, Hirata A, Inoue M, Yamamoto T. Localization of CD44 (Hyaluronan receptor) and hyaluronan in rat mandibular condyle. J Histochem Cytochem 2005; 53: 113-20.

[48] Helms JA, Schneider RA. Cranial skeletal biology. Nature 2003; 15: 423: 326-31.

[49] Corbel C, Lehmann A, Davison F. Expression of CD44 during early development of the chick embryo. Mech Dev 2000; 96: 1114.

[50] Roughly PJ. The structure and function of cartilage proteoglycans. Eur Cells Mater 2006; 12: 92-101.

[51] Danielson KG, Baribault H, Holmes DF, Graham H, Kadler KE, Iozzo RV. Targeted disruption of decorin leads to abnormal collagen fibril morphology and skin fragility. J Cell Biol 1997; 136: 729-43.

[52] $\mathrm{Xu}$ T, Bianco P, Fisher LW, et al. Targeted disruption of the biglycan gene leads to an osteoporosis-like phenotype in mice. Nat Genet 1998; 20: 78-82.

[53] Chakravarti S, Magnuson T, Lass JH, Jepsen KJ, LaMantia C, Carroll H. Lumican regulates collagen fibril assembly: skin fragility and corneal opacity in the absence of lumican. J Cell Biol 1998; 141: $1277-86$.

Received: December 22, 2008

Revised: February 4, 2009

Accepted: February 26, 2009

(c) Ababneh and Al-Khateeb; Licensee Bentham Open.

This is an open access article licensed under the terms of the Creative Commons Attribution Non-Commercial License (http: //creativecommons.org/licenses/ by-nc/3.0/) which permits unrestricted, non-commercial use, distribution and reproduction in any medium, provided the work is properly cited. 